\title{
Pendidikan Islam \\ Masa Rasulullah SAW
}

\author{
Suriadi \\ Email: suriadisambas@gmail.com \\ Institut Agama Islam Sultan Muhammad Syafiuddin Sambas
}

\begin{abstract}
This article discusses the transformation of Islamic education in the early period, that is from the epoch of the prophet Muhammad. In the period of the prophet Muhammad, Islamic education activity took place in its simple form, centered on the companions residents. Prophet Muhammad as uswatun hasanah and rabmatan lil 'alamin for those expecting the grace and the coming of the Day of Judgment is the first and foremost educators in the world of Islamic education. The transformation process of science, spiritualism internalization of values and emotional guidance of the Prophet Muhammad is incredible miracles and ordinary man may not be able to do so. Implementation of guidance of Islamic education in the time of Prophet Muhammad conducted in two phases which of Mecca, as the initial phase of guidance of Islamic education and the phase of Medina, as the improvement phase guidance of Islamic education.
\end{abstract}

Keywords: Islamic education, characteristics, phase of Mecca and Medina

\begin{abstract}
Abstrak: Artikel ini membahas tentang transformasi pendidikan Islam pada periode awal, yaitu dari zaman nabi Muhammad. Pada masa Nabi Muhammad SAW, kegiatan pendidikan Islam berlangsung dalam bentuknya yang sederhana, berpusat pada penghuni penghuni. Nabi Muhammad SAW sebagai uswatun hasanah dan rahmatan lil 'alamin bagi mereka yang mengharapkan anugerah dan hari kiamat adalah pendidik pertama dan terdepan di dunia pendidikan Islam. Proses transformasi sains, spiritualisme internalisasi nilai dan bimbingan emosional Nabi Muhammad adalah mukjizat yang luar biasa dan manusia biasa mungkin tidak dapat melakukannya. Implementasi pembinaan pendidikan Islam pada zaman Nabi Muhammad SAW dilakukan dalam dua tahap yaitu di Mekkah, sebagai tahap awal bimbingan pendidikan Islam dan fase Madinah, sebagai fasa perbaikan bimbingan pendidikan Islam.
\end{abstract}

Kata kunci: Pendidikan Islam, Karakteristik, Fase Mekkah dan Madinah

\section{A. Pendahuluan}

Sepanjang perjalanan hidup umat manusia terutama umat Islam, agama Islam yang dibawa dan disampaikan oleh Nabi Muhammad saw kepada umat 
manusia merupakan agama yang memperhatikan arti penting ilmu pengetahuan, baik secara teoritis maupun praktis. Secara normatif, Al-Quran dan Hadis menegaskan pentingnya pencarian ilmu untuk meraih prestasi kehidupan dunia dan akhirat, juga memberikan penghargaan yang sangat tinggi terhadap orangorang yang mengamalkan ilmunya untuk kemaslahatan manusia. Pesan moral keagamaan ini nampak dengan jelas pada Al-Quran surat pertama yang diturunkan kepada Nabi Muhammad saw. yaitu Al-Alaq ayat 1-5, mengandung esensi memerintahkan kepada manusia untuk mencari ilmu pengetahuan seluasluasnya melalui kegiatan membaca. Secara praktis, umat Islam telah sedang mengimplementasikan perintah iqra' tersebut dalam bentuk pendidikan Islam sejak masa Rasulullah saw. sampai dewasa ini.

Pendidikan Islam memiliki perjalanan historis yang cukup panjang, berkembang seiring dengan muncul agama Islam itu sendiri. Bagi masyarakat Arab, kedatangan Islam telah membawa perubahan mendasar pada budaya dan peradaban mereka dalam segala aspek kehidupan, termasuk dalam bidang pendidikan. Berdasarkan catatan sejarah, peradaban bangsa Arab pra Islam kurang memperhatikan pendidikan terbukti dengan minimnya jumlah orang Arab yang mampu membaca dan menulis. ${ }^{1}$

Pembahasan tentang pertumbuhan dan perkembangan pendidikan Islam terbagi ke dalam lima periode, antara lain:

1. Periode pembinaan pendidikan Islam, berlangsung pada zaman Nabi Muhammad saw.

2. Periode pertumbuhan pendidikan Islam, berlangsung sejak Nabi Muhammad saw wafat sampai masa akhir Bani Umayah yang diwarnai dengan perkembangan ilmu-ilmu naqliyah.

3. Periode kejayaan (puncak perkembangan) pendidikan Islam, berlangsung sejak permulaan Daulah Abbasiyah sampai dengan jatuhnya Bagdad, yang diwarnai oleh berkembangnya ilmu akliah dan timbulnya madrasah, serta memuncaknya perkembangan kebudayaan Islam.

4. Periode kemunduran pendidikan Islam, yaitu sejak jatuhnya Bagdad sampai jatuhnya Mesir ke tangan Napoleon yang ditandai dengan runtuhnya sendisendi kebudayaan Islam dan perpindahan pusat-pusat pengembangan kebudayaan ke dunia Barat.

${ }^{1}$ Muhammad Atiyyah Al-Abrasy, al-Tarbiyah al-Islamiyah, (Dar al-Qawmiyyah. 1964), hlm. 6. Lihat Hanun Asrohah, Sejarah Pendidikan Islam, (Jakarta: PT Logos Wacana Ilmu. 1999), cet. ke-1, hlm. 15. 
5. Periode pembaharuan pendidikan Islam, berlangsung sejak pendudukan Mesir oleh Napoleon sampai masa kini, yang ditandai dengan gejala-gejala kebangkitan kembali umat dan kebudayaan Islam. ${ }^{2}$

Terkait dengan kajian ini, penulis mencoba mengeksplorasi akar kemunculan dan perkembangan pendidikan Islam yang terfokus pada pembinaan pendidikan Islam pada masa Rasulullah saw.

\section{B. Teorisasi Pembinaan Pendidikan Islam pada Masa Rasulullah Saw}

Akar kemunculan pendidikan dalam Islam dimulai sejak masa Rasulullah saw. Pendidikan Islam, dalam pengertian umum, dapat dikatakan muncul dan berkembang seiring dengan kemunculan Islam itu sendiri, yakni berawal dari pendidikan yang bersifat informal berupa da'wah islamiyah untuk menyebarkan misi ajaran Islam, yang pada mulanya lebih berorientasi pada penanaman pokokpokok keyakinan (aqidah) dan ibadah pada umat Islam. ${ }^{3}$

Masa pembinaan pendidikan Islam yang dimaksud adalah masa di mana proses penurunan ajaran Islam kepada Muhammad saw. dan proses pembudayaannya (masuknya ke dalam kebudayaan manusia, sehinga diterima dan menjadi unsur yang menyatu dalam kebudayaan manusia) berlangsung. Masa tersebut berlangsung sejak Rasulullah menerima wahyu dan menerima pengangkatannya sebagai rasul, sampai dengan lengkap dan sempurnanya ajaran Islam menjadi warisan budaya umat Islam. ${ }^{4}$

Masa pembinaan pendidikan Islam berlangsung selama 22 atau 23 tahun sejak Rasulullah menerima wahyu pertama kali pada tanggal 17 Ramadhan 13 tahun sebelum hijrah atau bertepatan dengan 6 Agustus $610 \mathrm{M}$ sampai dengan wafatnya pada tanggal 12 Rabiul Awwal $11 \mathrm{H}$ atau bertepatan dengan 8 Juni 632 $\mathrm{M}^{5}$

Esensi pendidikan Islam yang dirintis oleh Rasulullah saw., baik pada periode Makkah maupun Madinah adalah dalam rangka mendukung dan memperkokoh posisi agama yang disebarkannya, yaitu Islam. Karena itu, materi

2Zuhairini, Sejarah Pendidikan Islam, (Jakarta: Bumi Aksara. 2011), cet. ke-11, hlm. 13.

${ }^{3}$ Saepudin Mashuri,"Transformasi Tradisi Keilmuan dalam Islam: Melacak Akar Kemunculan dan Perkembangan Institusi Pendidikan Islam”, Jurnal Hunafa, Vol. 4, No. 3, September 2007: 227-236, hlm. 228.

${ }^{4}$ Zuhairini, Sejarah Pendidikan, hlm. 14.

${ }^{5}$ Badri Yatim, Sejarah Peradaban Islam Dirasah Islamiyah II, Jakarta: Raja Grafindo Persada. 2006), hlm. 33. 
pendidikannya tidak jauh dari nilai-nilai ajaran Islam dan persoalan lain yang menjadi kebutuhan masyarakat Islam saat itu. ${ }^{6}$ Ajaran Islam yang dibawa Nabi Muhammad saw. berfungsi untuk meluruskan perkembangan budaya umat manusia yang ada pada zamannya dan memacu perkembangan selanjutnya, juga Nabi Muhammad saw. bertugas untuk menata kembali unsur-unsur budaya yang telah ada di kalangan bangsanya dan meletakkan unsur-unsur baru yang akan menjadi dasar bagi pengembangan budaya berikutnya. ${ }^{7}$ Oleh karena itu, pendidikan Islam tidak hanya diarahkan untuk membentuk pribadi kader Islam, tetapi juga membina aspek-aspek kemanusiaan sebagai hamba Allah untuk mengelola dan menjaga kesejahteraan alam semesta. Maka umat Islam dibekali dengan pendidikan tauhid, akhlak, amal ibadah, kehidupan sosial kemasyarakatan dan keagamaan, ekonomi, kesehatan, bahkan kehidupan bernegara. ${ }^{8}$

Pelaksanaan pembinaan pendidikan Islam pada masa Nabi Muhammad saw. dapat dibedakan menjadi dua tahap, baik dari segi waktu dan tempat penyelenggaraannya maupun dari segi isi dan materi pendidikannya, yaitu: 1) tahap/fase Makkah, sebagai fase awal pembinaan pendidikan Islam, dengan Makkah sebagai pusat kegiatannya, dan 2) tahap/fase Madinah, sebagai fase lanjutan (penyempurnaan) pembinaan/pendidikan Islam dengan Madinah sebagai pusat kegiatannya. ${ }^{9}$

Dengan demikian, masa pembinaan pendidikan Islam merupakan masa dimulainya peletakan sendi-sendi Islam untuk disampaikan dan ditanamkan oleh Nabi Muhammad saw kepada umatnya yang berlangsung selama 22 atau 23 tahun baik di Makkah maupun Madinah yang berdampak besar bagi pengembangan kehidupan selanjutnya.

\section{Pembinaan Pendidikan Islam di Makkah}

Sebagaimana diketahui bahwa Nabi Muhammad diutus untuk menyempurnakan Akhlak, dan misi ini merupakan misi pendidikan kenabian (pendidikan propetik). Dengan akhlaknya yang terpuji, syarat dengan nilai-nilai humanisme (insaniyah) dan spiritualisme (ilahiyah) di tengah-tengah umat yang

${ }^{6}$ Hisyam Nasyabe, Muslim Education Institutions,(Bairut: Libraire Du Liban. 1989), hlm. 6.

${ }^{7}$ Zuhairini, Sejarah Pendidikan, hlm. 14.

${ }^{8}$ Asrohah, Sejarah Pendidikan, hlm. 15.

${ }^{9}$ Zuhairini, Sejarah Pendidikan, hlm. 18. 
hampir saja tidak berprikemanusiaan, Nabi Muhammad saw mendapat gelar tertinggi al-Amin. ${ }^{10}$ Perjalanan pembinaan pendidikan Islam pada masa nabi Muhammad Saw. dimulai dengan kepekaan Nabi Muhammad Saw terhadap kondisi sosiokultural dan politik yang dilanjutkan dengan suatu proses mempertahankan tradisi Nabi Ibrahim yaitu tabah dalam mencari kebenaran hakiki, menjauhkan diri dari keramaian dan sikap hedonisme dengan berkontemplasi (ber-tahannus) di Gua Hira. Maka, pada tanggal 17 Ramadhan turunlah wahyu pertama, surat al-Alaq ayat 1-5 sebagai babak baru fase dimulainya pendidikan Islam di Makkah.

Nabi Muhammad saw memberikan petunjuk dan pengajaran yang berpedoman pada al-Qur'an atau wahyu-wahyu yang diterimanya. Sistem pengajarannya adalah menjelaskan pada manusia tentang makna wahyu yang telah diterimanya sekaligus memberikan petunjuk serta tauladan bagaimana melaksanakan ajaran wahyu tersebut. Pelajaran dan contoh teladan yang diajarkan Nabi Muhammad saw itu diharapkan menjadi landasan yang kokoh untuk segala perbuatan manusia dalam hidup dan kehidupannya sehari-hari. ${ }^{11}$

\section{Tahapan Pendidikan Islam}

a. Tahap pendidikan Islam secara rahasia dan perorangan

Nabi Muhammad saw pada awal penyebaran agama Islam bertindak selaku pendidik dan dilakukan secara bertahap. Pada awal turunnya wahyu pertama (the first revelation) surat 74 ayat $1-7$, pola pendidikan yang dilakukan adalah secara sembunyi-sembunyi mengingat kondisi sosial politik yang belum stabil, dimulai dari dirinya sendiri dan kelurga dekatnya. Mula-mula Rasulullah mendidik istrinya Khadijah untuk beriman kepada dan menerima petunjuk Allah, kemudian diikuti oleh Anak angkatnya Ali bin Abi Thalib dan Zaid bin Haritsah (seorang pembantu rumah tangganya yang kemudian diangkat menjadi anak angkatnya). Kemudian sahabat karibnya Abu Bakar Siddiq. Secara berangsur-angsur ajakan tersebut disampaikan secara meluas, tetapi masih terbatas di kalangan keluarga dekat dari suku Quraisy saja, seperti Usman bin

10 Yatim, Sejarah Peradaban, hlm. 17.

${ }^{11}$ Sakka Hasan, "Kajian tentang Pendidikan Islam Masa Rasulullah dan Khulafaur Rasyidin," Selami IPS, Edisi No. 25, Vol. 1, tahun VIII Desember 2008, hlm. 103. (isjd.pdii.lipi.go.id/admin/jurnal/1250899109_1410-2323.pdf. saka hasan), akses tanggal 7 September 2017. 
Affan, Zubair bin Awwam, Sa'ad bin Abi Waqas, Abdurrahman bin Auf, Thalhah bin Ubaidillah, Abu Ubaidillah bin Jarrah, Arqam bin Arqam, Fatimah binti Khattab, Said bin Zaid, dan beberapa orang lainnya, mereka semua disebut Assabiquna alawwalun. ${ }^{12}$

Kegiatan pendidikan diselenggarakan di rumah-rumah sahabat, yang paling terkenal adalah Dar al-Arqam sebagai derivasi langsung dari nama seorang sahabat pemilik rumah yang dijadikan tempat pembelajaran antara Rasulullah saw. dan umat Islam. ${ }^{13}$

b. Tahap pendidikan Islam secara terang-terangan

Pendidikan secara sembunyi-sembunyi berlangsung selama tiga tahun sampai turun wahyu berikutnya yang memerintahkan dakwah secara terbuka dan terang-terangan. Ketika wahyu tersebut turun beliau mengundang keluarga dekatnya untuk berkumpul di bukit Shafa, menyerukan agar berhati-hati terhadap azab yang keras di kemudian hari bagi orang-orang yang tidak mengakui Allah sebagai Tuhan YME dan Muhammad sebagai utusan-Nya. Perintah dakwah secara terang-terangan dilakukan oleh Rasulullah seiring dengan jumlah sahabat yang semakin banyak untuk meningkatkan jangkauan seruan dakwah, karena diyakini dengan dakwah tersebut banyak kaum Quraisy yang akan masuk Islam. Di samping itu, keberadaan rumah Arqam bin Arqam sebagai pusat dan lembaga pendidikan Islam sudah diketahui oleh Kuffar Quraisy. ${ }^{14}$

c. Tahap pendidikan Islam untuk umum

Hasil seruan secara terang-terangan yang terfokus kepada keluarga dekat, kelihatannya belum maksimal sesuai dengan apa yang diharapkan. Maka, Rasulullah mengubah strategi dakwahnya dari seruan yang yang terfokus kepada keluarga dekat beralih kepada seruan umum, umat manusia secara keseluruhan.

Seruan dalam sekala internasional tersebut didasarkan pada perintah Allah surat al-Hijr ayat 94-95. Sebagai tindak lanjut dari perintah Allah tersebut,

12 Kamaruzzaman, "Pola Pendidikan Islam Pada Periode Rasulullah: Makkah dan Madinah", Samsul Nizar (ed.), Sejarah Pendidikan Islam: Menelusuri Jejak Sejarah Pendidikan Era Rasulullab Samapai Indonesia, (Jakarta: Kencana. 2007), cet. ke-1. hlm. 32. Lihat Asrohah, Sejarah Pendidikan, hlm. 12.

${ }^{13}$ Mashuri, Transformasi Tradisi, hlm. 229.

${ }^{14}$ Kamaruzzaman, Pola Pendidikan, hlm. 33. 
pada musim haji Rasulullah mendatangi kemah-kemah para jamaah haji. Pada awalnya tidak banyak yang menerima, kecuali sekelompok jama'ah haji dari Yastrib, Kabilah Khazraj yang menerima dakwah secara antusias. Dari sinilah sinar Islam memancar ke luar Makkah. ${ }^{15}$

\section{Materi Pendidikan Islam}

Materi pendidikan Islam di Makkah terbagi ke dalam dua bagian, yaitu: Pertama, materi pendidikan tauhid, materi ini lebih difokuskan untuk memurnikan ajaran tauhid yang di bawa Nabi Ibrahim yang telah diselewengkan oleh masyarakat jahiliyah. Secara teori inti sari ajaran tauhid terdapat dalam kandungan surat al-Fatihah ayat 1-7 dan surat al-Ikhlas ayat 1-5.

Secara praktis pendidikan tauhid diberikan melalui cara-cara yang bijaksana, menuntun akal pikiran dengan mengajak umatnya untuk membaca, memperhatikan dan memikirkan kekuasaan dan kebesaran Allah dan diri manusia sendiri. Kemudian beliau mengajarkan cara bagaimana mengaplikasikan pengertian tauhid tersebut dalam kehidupan sehari-sehari. Rasulullah langsung menjadi contoh bagi umatnya. Hasilnya, kebiasaan masyarakat Arab yang memulai perbuatan atas nama berhala, diganti dengan ucapan bismillahirrabmanirrabim. Kebiasaan menyembah berhala, diganti dengan mengagungkan dan menyembah Allah SWT. ${ }^{16}$

Selanjutnya, materi ini lebih difokuskan untuk memurnikan ajaran tauhid yang telah dibawa oleh nabi Ibrahim dan telah diselewengkan oleh masyarakat jahiliyah. Muhammad memperoleh kesadaran dan penghayatan yang mantap tentang ajaran tauhid. Secara teoritis intisari ajaran tauhid tercermindalam surat al Fatihah. Pokok-pokok kandungannya adalah :

a. Bahwa Allah adalahpencipta alam semesta yang sebenarnya., satu-satunya yang menguasai dan mengatur alam ini, sehingga alam merupakan tempat yang sesuai dengan kehidupan manusia. Maka Dialah yang berhak untuk mendapat pujian.

b. Allah telah memberikan nikmat yang berupa segala keperluan manusia ditambah dengan petunjuk dan bimbingan dengan penuh kasih sayang, al Rahman al Rahim.

${ }^{15}$ Ibid.

${ }^{16}$ Zuhairini, Sejarah Pendidikan, hlm. 23-26. 
c. Allah adalah raja hari kemudian yang akan menghitung amal perbuatan manusia di dunia yang akan diperhitungkan di alam akhirat.

d. Allah adalah sesembahan yang sebenarnya dan satu-satunya. Segala perbuatan dan pengabdian manusia harus dikerjakan karena Allah.

e. Allah adalah penolong yang sebenarnya

f. Allah yang membimbing dan memberi petunjuk kepada manusia dalam menjalankan kehidupan di dunia.

Kedua, materi pengajaran al-Qur'an. Materi ini dapat dirinci kepada beberapa bagian sebagai berikut:

a. Materi baca tulis Al-Qur'an (imla' dan iqra'), dengan materi ini diharapkan agar kebiasaan orang Arab yang sering membaca syair-syair indah, diganti dengan membaca al-Qur'an sebagai bacaan yang lebih tinggi nilai sastranya.

b. Materi menghafal ayat-ayat al-Qur'an atau menghafalkan ayat-ayat al-Qur'an.

c. Materi pemahaman al-Qur'an atau materi fahmi al-Qur'an atau tafsir alQuran, tujuan materi ini adalah meluruskan pola pikir umat Islam yang dipengaruhi pola pikir jahiliyah. Di sinilah letaknya fungsi hadits sebagai bacaan al-Qur'an. ${ }^{17}$

Materi pengajaran al Qur'an diajarkan Rasulullah Saw dengan baik dan sempurna. Di antara faktor yang mendukung diajarkannya al Qur'an adalah :

a. Bangsa Arab pada masa itu dikenal sebagai masyarakat yang ummi/ tidak dapat membaca dan menulis. Tradisi budaya mereka adalah budaya lisan. Mereka mempunyai tradisi menghafal syair dan puisi yang indah.

b. Allah telah menyampaikan al Qur'an secara berangsur-angsur, sedikit demi sedikit sehingga memudahkan bagi Nabi Muhammad untuk mengajarkan al Qur'an kepada umatnya, dengan jalan menghafal. Potenai hafalan para sahabat telah menolong untuk menghafal ayat-ayat yang disampaikan oleh anabi.

Materi-materi pendidikan al-Qur'an yang tersebut pada masa Nabi berada di Makkah di laksanakan di Kuttab. Kuttab berasal dari kata kataba yang berarti menulis atau tempatmenulis. Jadi kuttab adalah tempat belajar menulis. Pada mulanya, kuttab dilaksanakan di rumah guru-guru yang mempunyai

${ }^{17}$ Ibid., hlm. 27-30. 
kompetensi dalam itu dan yang diajarkan adalah semata-mata membaca dan menulis. $^{18}$

Selanjutnya, Mahmud Yunus mengemukakan bahwa pembinaan pendidikan Islam di Makkah meliputi:

a. Pendidikan keagamaan, yaitu hendaklah membaca dengan nama Allah semata-mata dan jangan dipersekutukan dengan nama berhala.

b. Pendidikan aqliyah dan ilmiyah, yaitu mempelajari kejadian manusia dari segumpal darah dan kejadian alam semesta. Allah mengajarkan demikian itu kepada orang-orang yang mau menyelidiki dan membahasnya, sedangkan mereka dahulu belum mengetahuinya.

c. Pendidikan akhlak dan budi pekerti, Nabi Muhammad saw. mengajarkan sahabatnya agar berakhlak baik sesuai dengan ajaran tauhid.

d. Pendidikan jasmani (kesehatan), yaitu mementingkan kebersihan pakaian, badan dan tempat kediaman. ${ }^{19}$

\section{Metode Pendidikan Islam}

Metode pendidikan yang dilakukan Rasulullah Saw. dalam membidik sahabatnya antara lain: a) metode ceramah, menyampaikan wahyu yang baru diterimanya dan memberikan penjelasan-penjelasan serta keteranganketerangannya; b) dialog, misalnya dialog Rasulullah dengan Mu'az bin Jabal ketika Mu'az akan diutus sebagai qadi ke negeri Yaman, dialog antara Rasulullah dengan para sahabat untuk mengatur startegi perang; c) diskusi atau tanya jawab, sering sahabat bertanya kepada Rasulullah tentang suatu hukum, kemudian Rasulullah menjawab; d) metode perumpamaan, misalnya orang mukmin itu laksana satu tubuh, bila sakit salah satu anggota tubuh maka anggota tubuh lainnya akan merasakannya; e) metode kisah, misalnya kisah beliau dalam perjalanan isra mi'raj dan kisah tentang pertemuan antara Nabi Musa dengan Nabi Khaidir; f) metode pembiasaan, membiasakan kaum muslimin shalat berjamaah; dan g) metode hafalan misalnya para sahabat dianjurkan untuk menjaga al-Qur'an dengan menghafalnya. ${ }^{20}$

${ }^{18}$ Ahmad Syalabi, Sejarah Pendidikan Islam, Penerj. Mukhtar Yahya Et. M.SANUSI Latief, BuLAN Bintang, Jakarta,tt hal.45.

${ }^{19}$ Mahmud Yunus, Sejarab Pendidikan Islam, (Jakarta: Hidakarya Agung. 1989), hlm. 5-6.

${ }^{20}$ Kamaruzzaman, Pola Pendidikan, hlm. 35. 


\section{Kurikulum Pendidikan Islam}

Kurikulum pendidikan Islam pada periode Rasulullah baik di Makkah maupun Madinah adalah al-Qur'an yang Allah wahyukan sesuai dengan kondisi dan situasi, kejadian dan peristiwa yang dialami umat Islam pada saat itu, karena itu dalam praktiknya tidak saja logis dan rasional, tetapi juga fitrah dan pragmatis. Hasil cara yang demikian dapat dilihat dari sikap rohani dan mental para pengikutnya. ${ }^{21}$ Oleh karena itu, rumusan dan materi pendidikan, sekitar 14 abad yang lalu menggambarkan Rasulullah telah menerapkan kurikulum berbasis masyarakat. $^{22}$

\section{Lembaga Pendidikan Islam}

Lembaga pendidikan Islam pada fase Makkah ada dua macam tempat, yaitu :

a. Rumah Arqam bin Arqam merupakan tempat pertama berkumpulnya kaum muslimin beserta Rasulullah untuk belajar hukum-hukum dan dasar-dasar ajaran Islam. Rumah ini merupakan lembaga pendidikan pertama atau madrasah yang pertama dalam Islam adapun yang mengajar dalam lembaga tersebut adalah Rasulullah sendiri.

b. Kuttab. Pendidikan kuttab tidak sama dengan pendidikan yang diadakan di rumah Arqam bin Arqam, pendidikan di rumah Arqam bin Arqam kandungan materi tentang hukum Islam dan dasar-dasar agama Islam, sedangkan pendidikan di kuttab pada awalnya lebih terfokus pada materi baca tulis sastra, syair arab, dan pembelajaran berhitung namun setelah datang Islam materinya ditambah dengan materi baca tulis al-Quran dan memahami hukum-hukum Islam. Adapun guru yang mengajar di kuttab pada era awal Islam adalah orang-orang non Islam. Dalam sejarah pendidikan Islam istilah kuttab telah dikenal di kalangan bangsa arab pra Islam, secara etimologi kuttab berasal dari bahasa Arab yakni kataba,

${ }^{21}$ Ibid., hlm. 36.

22Zaenal Efendi Hasibuan, "Profil Rasulullah sebagai Pendidik Ideal: Telaah Pola Pendidikan Islam Era Rasulullah Fase Mekkah dan Madinah", Samsul Nizar (ed.), Sejarah Pendidikan Islam: Menelusuri Jejak. Sejarah Pendidikan Era Rasulullah Samapai Indonesia, (Jakarta: Kencana. 2007), cet. ke-1, hlm. 26. 
yaktubu, kitaaban yang artinya telah menulis, sedang menulis dan tulis, sedangkan maktab artinya meja atau tempat menulis. ${ }^{23}$

Ditinjau dari pelaksanaan pembelajaran, karena kondisi yang masih sangat sederhana maka Rasulullah menerapkan sistem halaqah yang berlangsung di rumah, masjid, dan kuttab. Sistem halaqah adalah sistem melingkar antara peserta didik lututnya saling bersentuhan, sementara guru duduk pada posisi sentral. Sistem seperti ini menyentuh dimensi kognitif, aspek emosional dan spiritual, serta rasa persaudaraan yang tinggi antar sesama. ${ }^{24}$

\section{Pembinaan Pendidikan Islam di Madinah}

Hijrah dari Makkah ke Madinah bukan hanya sekedar berpindah dan menghindarkan diri dari tekanan dan ancaman kaum Quraisy dan penduduk Makkah yang tidak menghendaki pembaharuan terhadap ajaran nenek moyang mereka, tetapi juga mengandung maksud untuk mengatur potensi dan menyusun kekuatan dalam menghadapi tantangan-tangan lebih lanjut, sehingga akhirnya nanti terbentuk masyarakat baru yang di dalamnya bersinar kembali mutiara tauhid warisan Ibrahim yang akan disempurkan oleh Muhammad saw melalui wahyu.

Kedatangan Nabi Muhammad saw bersama kaum muslimin Makkah, disambut oleh penduduk Madinah dengan gembira dan penuh rasa persaudaraan. Maka Islam mendapatkan lingkungan baru yang bebas dari ancaman para penguasa Quraisy Makkah, lingkungan yang memungkinkan bagi Nabi Muhammad saw untuk meneruskan dakwah, menyampaikan ajaran Islam dan menjabarkannya dalam kehidupan sehari-hari.

Oleh karena itu kalau pada fase Mekkah ciri pokok pembinaan penidikan Islam adalah pendidikan tauhid maka pada fase Madinah ciri pokok pembinaan pendidikan Islam dapat dikatakan sebagai pendiikan sosial politik. ${ }^{25}$

\section{Lembaga Pendidikan Islam}

Setelah Rasulullah saw. hijrah ke Madinah, pendidikan Islam dapat dijalankan secara leluasa, sistematis, dan terstruktur dengan mendirikan beberapa

${ }^{23}$ Ibid., hlm. 37.

${ }^{24}$ Hasibuan, Profil Rasulullah, hlm. 26.

25 Zuhairini, Sejarah Pendidikan Islam, Bumi Aksara, 1992 hal.33. 
lembaga pendidikan Islam. Langkah pertama yang dilakukan Rasulullah saw. adalah mendirikan masjid sebagai sentral tempat ibadah dan mengatur kehidupan umat Islam dengan petunjuk ajaran Islam. Masjid, disamping sebagai tempat ibadah juga digunakan sebagai tempat pendidikan untuk mengajarkan ilmu-ilmu keagamaan. Bagi anak-anak Islam, Rasulullah saw. mendirikan kuttab sebagai pusat pendidikan dalam hal membaca dan menulis. ${ }^{26}$

Secara teknis, proses pendidikan pada periode ini tidak hanya dilaksanakan oleh umat Islam, tetapi juga oleh tawanan perang yang belum masuk Islam. Dengan kemampuan membaca dan menulis yang mereka miliki, diberikan tanggung jawab oleh Rasulullah saw. untuk melaksanakan pendidikan bagi anak-anak muslim sebagai tebusan pembebasan atas status mereka sebagai tawanan perang. ${ }^{27}$

\section{Materi Pendidikan Islam}

Pada fase Madinah materi pendidikan yang diberikan cakupannya lebih kompleks dibandingkan dengan materi pendidikan fase Makkah. Materi pendidikan Islam itu antara lain:

a. Pendidikan ukhuwah (persaudaraan) antara kaum muslimin. Dalam pelaksanaan pendidikan ukhuwah ini, Nabi Muhammad saw bertitik tolak dari struktur kekeluargaan yang ada pada masa itu. Untuk mempesatukan keluarga itu Nabi Muhammad saw berusaha untuk mengikatnya menjadi satu kesatuan yang terpadu. Mereka dipersaudarakan karena Allah bukan karena yang lain. Sesuai dengan konstitusi Madinah bahwa antara orang yang beriman tidak boleh membiarkan saudaranya menanggung beban hidup dan utang yang berat di antara sesama manusia.

b. Pendidikan kesejahteraan sosial. Terjaminnya kesejahteraan sosial tergantung pertama-tama pada terpenuhinya kebutuhan pokok dari pada kehidupan sehari-hari. Untuk itu, semua orang harus herus bekerja mencari nafkah. Nabi Muhammad saw selalu memerintahkan kepada kaum Muhajirin yang telah dipersaudarakan dengan kaum Ansor agar

${ }^{26}$ Ruswan Thoyib,. "Development of Muslim Educational System in The Classical Period (600-1000 A.D.) an Overview", The Dynamic of Islamic Civilization (Satu Dasawarsa Program Pembibitan), (Yogyakarta: Titian Ilahi Press. 1998), hlm. 56.

${ }^{27}$ K. Ali, A Study of Islamic History, (Delhi: Idarah al-Adabiyah. 1980), hlm. 79. 
bekerjasama dengan saudara-saudaranya tersebut. Atau dengan pengertian salah satu persoalan yang dapat mewujudkan kesejahteraan sosial adalah memiliki pekerjaan tetap. Untuk mengatasi masalah ini, Nabi memerintahkan kepada kaum Muhajirin yang telah dipersaudarakan dengan kaum Anshar agar mereka bekerja sama dengan saudara-saudaranya. Untuk itu nabi menetapkan aturan yang berhubungan dengan pengaturan dan penggunaan kekayaan tersebut agar tidak menumpuk pada orang-orang kaya dan agar mereka yang mempunyai tugas khusus juga dapat terpenuhi kebutuhan kehidupannya.

c. Pendidikan kesejahteraan keluarga kaum kerabat. Nabi Muhammad saw berusaha untuk memperbaiki keadaan itu dengan memperkenalkan dan sekaligus menerapkan sistem kekeluargaan ke kerabat baru yang berdasarkan takwa kepada Allah. Selain itu, Nabi Muhammad berusaha untuk memperkenalkan dan sekaligus menerapkan sistem kekeluargaan dan kekerabatan yang berdasarkan taqwa kepada Allah. Nabi memperkenalkan sistem kekeluargaan yang mengakui hak-hak induvidu, hak-hak keluarga ( pasangan suami istri ) dan kemurnian keturunannya dalam kehiupan kekerabatan dan kemasyarakatan yang adil dan seimbang, seperti yang tertuang alam al Qur'an surat al Hujurat ayat 13.

d. Pendidikan hankam (pertahanan dan keamanan) dakwah Islam. Masyarakat muslimin merupakan suatu negara di bawah bimbingan Nabi Muhammad saw yang mempunyai kedaulatan. Ini merupakan dasar bagi usaha dakwahnya untuk menyampaikan ajaran Islam kepada seluruh umat manusia secara bertahap..$^{28}$ Atau adanya pasukan atau satuan pengamanan dan pertahanan adalah satu hal mutlak yang harus ada untuk mendukung dilakukannya dakwah Islam. Satuana pengamanan tersebut mula-mula untuk melakukan pengamatan dan pengamanan wilayah sekitar Madinah, tapi kemudian menjadi pasukan yang ditugaskan untuk mengadakan perjanjian perdamaian yang melibatkan kaum Anshor. Plibatan kaum Anshor ini merupakan aplikasi dari isi baiat dan ikrar akbar yang isinya ikrar antara nabi Muhammad dengan kaum Muslimun Madinah akan saling membela dan sehidup semati.

${ }^{28}$ Kamaruzzaman, Pola Pendidikan, hlm. 38-39. 
Materi pendidikan Islam selain yang disebut di atas, Sakka Hasan mengemukakan bahwa pokok-pokok pendidikan dan pengajaran Nabi Muhammad saw. di Madinah yaitu bidang keimanan, bidang peribadatan, bidang muamalah, bidang akhlak (individu dan sosial), bidang kesehatan (jasmani), bidang politik, ekonomi, sosial, budaya, serta ajaran-ajaran yang mencakup keseluruhan aspek hidup dan kehidupan manusia, baik kehidupan individu, keluarga, maupun masyarakat untuk keselamatannya dunia dan akhirat. ${ }^{29}$

Dengan demikian, pelaksanaan pembinaan pendidikan Islam di Makkah dan Madinah dapat dilihat pada tabel berikut ini.

\begin{tabular}{|c|c|c|}
\hline Aspek & Makkah & Madinah \\
\hline $\begin{array}{l}\text { Tahapan pelaksanaan } \\
\text { Pendidikan }\end{array}$ & $\begin{array}{l}\text { Tahap rahasia dan } \\
\text { perorangan, tahap terang- } \\
\text { terangan, dan tahap } \\
\text { untuk umum }\end{array}$ & $\begin{array}{l}\text { Tahap untuk umum atau } \\
\text { seruan dalam skala } \\
\text { internasional }\end{array}$ \\
\hline Materi & $\begin{array}{l}\text { Tauhid, Pengajaran al- } \\
\text { Qur'an, ibadah, akhlak, } \\
\text { dan pendidikan jasmani }\end{array}$ & $\begin{array}{l}\text { keimanan, ibadah, } \\
\text { muamalah, akhlak } \\
\text { (individu dan sosial), } \\
\text { kesehatan (jasmani), } \\
\text { politik, ekonomi, sosial, } \\
\text { budaya, serta ajaran- } \\
\text { ajaran yang mencakup } \\
\text { keseluruhan aspek hidup } \\
\text { dan kehidupan manusia }\end{array}$ \\
\hline Metode & $\begin{array}{l}\text { Ceramah, dialog, diskusi, } \\
\text { tanya jawab, } \\
\text { perumpamaan, kisah, } \\
\text { pembiasaan, dan hafalan. }\end{array}$ & Sama \\
\hline Kurikulum & $\begin{array}{ll}\text { 1. } & \text { Al-Qur'an } \\
\text { 2. } & \text { Menerapkan } \\
& \text { kurikulum berbasis } \\
& \text { masyarakat }\end{array}$ & Sama \\
\hline $\begin{array}{l}\text { Lembaga dan sistem } \\
\text { Pengajaran }\end{array}$ & $\begin{array}{l}\text { Rumah Arqam bin } \\
\text { Arqam dan Kuttab }\end{array}$ & $\begin{array}{l}\text { Rumah para sahabat dan } \\
\text { masjid yang multi fungsi }\end{array}$ \\
\hline
\end{tabular}

${ }^{29}$ Hasan, Kajian tentang Pendidikan, hlm. 104. 


\section{E. Kesimpulan}

Pelaksanaan pembinaan pendidikan Islam pada masa Nabi Muhammad saw. Dilaksanakan dalam dua fase yaitu fase Makkah, sebagai fase awal pembinaan pendidikan Islam dan fase Madinah. Sebagai fase penyempurnaan pembinaan/pendidikan Islam. Kedudukan Rasulullah sebagai ushwatun hasanah dalam segala aspek, dapat dilihat dari peranannya yang sangat luar biasa dalam pengelolaan dan pengembangan sistem pendidikan. Meskipun dengan menggunakan sarana dan prasarana yang sangat sederhana telah berhasil mengeluarkan outcome pendidikan yang berkualitas fikir, dzikir, dan amal shaleh.

Pola pendidikan pada masa Rasulullah tidak terlepas dari dasar, tujuan, metode, materi, kurikulum, pendidik, peserta didik, lembaga, dan sebagainya yang berhubungan dengan pelaksanaan pendidikan Islam, baik secara teoritis maupun praktis. Selanjutnya metode yang digunakan adalah: metode ceramah, tanya jawab, diskusi, pembiasaan, metode kisah, metode amsal dan lain sebagainya. 
154 | BELAJEA : Jurnal Pendidikan Islam, Vol. 2, No. 02, 2017

\section{Daftar Pustaka}

Aly, Sejarah Pendidikan Islam Indonesia, CV.Pustaka Setia, Bandung, 1999

Asari,Hasan, Menyingkap zaman keemasan Islam, Mizan, Bandung, 2004.

Al Syaibany, Omar Muhammad al Toumy,Falsafah al Tarbiyah al Islamiyah, terj.Hasan Langgulung, Filsafat Pendidikan Islam; Bulan Bintang, Jakarta,1979.

Badri Yatim. Sejarah Peradaban Islam Dirasah Islamiyah II, Jakarta: Raja Grafindo Persada. 2006.

Cholil, MunawarKelengkaan Tarikh Nabi SAW.,Bulan Bintang. Jakarta; 1969.

Dauly,Haidar Putra Sejarah pertumbuhan dan pembaharuan Pendidikan Islam di Indonesia, Kencana Prenada M edia Group, Jakarta, 2007.

Hanun Asrohah. Sejarah Pendidikan Islam, Jakarta: PT Logos Wacana Ilmu. 1999.

Hisyam Nasyabe. Muslim Education Institutions, Bairut: Libraire Du Liban. 1989.

K. Ali. A Study of Islamic History, (Delhi: Idarah al-Adabiyah. 1980.

Kamaruzzaman, "Pola Pendidikan Islam Pada Periode Rasulullab: Makkah dan Madinab", Samsul Nizar (ed.), Sejarah Pendidikan Islam: Menelusuri Jejak Sejarab Pendidikan Era Rasulullah Samapai Indonesia, Jakarta: Kencana, cet. ke-1. 2007.

Marimba Ahmad D., Pengantar Filsafat Pendidikan Islam,Al Ma'arif, Bandung; 1998.

Mahmud Yunus. Sejarah Pendidikan Islam, Jakarta: Hidakarya Agung. 2007.

Muhammad Atiyyah Al-Abrasy. al-Tarbiyah al-Islamiyah, Dar al-Qawmiyyah, 1999. 
Nasution Harun, Pembaharuan Dalam Islam, Bulan Bintang. Jakarta;. 1991

Ramayulis, Sejarah Pendidikan Islam, Kalam Mulia, Jakarta, 2011

-------, Sejarah Pendidikan Islam, Radar Jaya, Jakarta, 2012.

Ruswan Thoyib. 1998. "Development of Muslim Educational System in The Classical Period (600-1000 A.D.) an Overview", The Dynamic of Islamic Civilization (Satu Dasawarsa Program Pembibitan), Yogyakarta: Titian Ilahi Press.

Saepudin Mashuri,"Transformasi Tradisi Keilmuan dalam Islam: Melacak Akar Kemunculan dan Perkembangan Institusi Pendidikan Islam", Jurnal Hunafa, Vol. 4, No. 3, September 2007: 227-236.

Sakka Hasan, "Kajian tentang Pendidikan Islam Masa Rasulullah dan Khulafaur Rasyidin," Selami IPS, Edisi No. 25, Vol. 1, tahun VIII Desember 2008, hlm. 103. (isjd.pdii.lipi.go.id/admin/jurnal/1250899109_1410-2323.pdf. saka basan), akses tanggal 7 September 207.

Zaenal Efendi Hasibuan. 2007. "Profil Rasulullah sebagai Pendidik Ideal: Telaab Pola Pendidikan Islam Era Rasulullah Fase Mekkah dan Madinab", Samsul Nizar (ed.), Sejarah Pendidikan Islam: Menelusuri Jejak Sejarah Pendidikan Era Rasulullah Samapai Indonesia, (Jakarta: Kencana. 2007), cet. ke-1.

Zuhairini, Sejarah Pendidikan Islam, Bumi Aksara, 1992. 2011. Sejarah Pendidikan Islam, Jakarta: Bumi Aksara 
156 | BELAJEA : Jurnal Pendidikan Islam, Vol. 2, No. 02, 2017 